\title{
Lymphocyte activation after exposure to swine dust: a role of humoral mediators and phagocytic cells
}

\author{
C. Müller-Suur*,\#, P.H. Larsson*, K. Larsson*, J. Grunewald ${ }^{\#}$
}

\begin{abstract}
Lymphocyte activation after exposure to swine dust: a role of humoral mediators and phagocytic cells. C. Müller-Suur, P.H. Larsson, K. Larsson, J. Grunewald. (C)ERS Journals Ltd 2002.

ABSTRACT: Exposure to swine dust causes intense airway inflammation with multifold increase in inflammatory cells and secretion of pro-inflammatory cytokines. This in vitro study focuses on the swine-dust activation of lymphocytes in whole blood, in phagocytedepleted whole blood and in peripheral blood mononuclear cells (PBMC), in order to investigate whether phagocytic cells and/or soluble mediators are involved in the activation of T-cells following exposure to organic dust from a swine confinement house.

T-cell activation was analysed by flow cytometry with double staining for CD3 and the activation marker CD69.

Swine dust $(50 \mu \mathrm{g})$ incubated $(24 \mathrm{~h})$ with heparinized whole blood was shown to activate $27.6 \%$ of the T-cells, while swine dust incubated with whole blood depleted from phagocytic cells or PBMC only activated $4.5 \%$ and $4.8 \%$ of the T-cells, respectively. Plasma separated from whole blood preincubated with swine dust for $24 \mathrm{~h}$ stimulated as much as $32.4 \%$ of PBMC T-cells and contained high levels of interleukin (IL)-12 $(14 \mathrm{pg} \cdot \mathrm{mL})$ and interferon (IFN)- $\gamma\left(2284 \mathrm{pg} \cdot \mathrm{mL}^{-1}\right)$, while plasma from PBMC incubated with swine dust contained low levels of IL-12 $\left(2 \mathrm{pg} \cdot \mathrm{mL}^{-1}\right)$ and IFN- $\gamma\left(196 \mathrm{pg} \cdot \mathrm{mL}^{-1}\right)$.

This study demonstrates that activation of T-cells by organic dust from a swine confinement building seems to require phagocytic cells, most likely acting through the release of soluble mediators. Also, conditioned plasma from swine-dust exposed whole blood, which was capable of activating $T$-cells, contained high concentrations of interleukin-12 and interferon- $\gamma$.

Eur Respir J 2002; 19: 104-107.
\end{abstract}

*Respiratory \& Allergy Division, National Institute for Working Life Stockholm, Sweden. ${ }^{\text {\#}}$ Dept of Medicine, Division of Respiratory Medicine, Lung Research Laboratory, Karolinska Hospital Stockholm, Sweden.

Correspondence: C. Müller-Suur, Respiratory \& Allergy Division Dept of Occupational Medicine, National Institute for Working Life, SE-11279 Stockholm, Sweden.

Fax: 4687309897

Keywords: Dust lymphocytes

peripheral blood mononuclear cells soluble mediators whole blood

Received: March 262001

Accepted after revision September 7 2001
Three hours exposure to dust in a swine confinement building causes intense airway inflammation, with a multifold increase of inflammatory cells, predominantly neutrophils, in healthy volunteers [1]. The exposure also induces secretion of pro-inflammatory cytokines such as tumour necrosis factor (TNF)- $\alpha$, interleukin (IL)-1, IL-6, and IL-8 in the airways in vivo as assessed by bronchoalveolar lavage (BAL) [2-4]. The most probable sources for these cytokines are alveolar macrophages [5] and epithelial cells [6]. Previous in vivo findings have shown increased numbers of T- and B- lymphocytes in BAL fluid following exposure to dust in a swine confinement house, but the proportion of T-lymphocytes in relation to the total amount of lymphocytes, was unaltered [7]. In the same study it was also demonstrated that exposure to organic dust induced activation (increased expression of the activation markers CD69, CD25 and human leukocyte antigen-DR) of T-lymphocytes in vivo [7]. Furthermore, dust from swine confinement buildings activates T-cells in a dose- and time-response manner in vitro when incubated with peripheral whole blood from healthy subjects [8].

The in vivo lymphocyte activation caused by inhaled organic dust may comprise a specific activation of the T-lymphocytes through the T-cell antigen receptor. There is also a possibility that the activation of T-cells is mediated by nonspecific mechanisms in which release of T-cell activating soluble mediators from cells other than lymphocytes may be involved.

The aim of the present in vitro study thus was to elucidate whether phagocytic cells and/or soluble mediators are involved in the activation of T-cells following exposure to organic dust from a swine confinement house.

\section{Materials and methods}

\section{Subjects}

Venous blood was collected from seven (5 female), nonallergic, nonsmoking, healthy subjects, with no previous exposure for swine dust, and with a mean age of 43 (range 26-58) yrs. All subjects gave their informed consent and the study was approved by the Ethics Committee of Karolinska Institute, Stockholm, Sweden.

\section{Stimulation with dust}

Dust collected $\sim 1.5 \mathrm{~m}$ above the floor in a swine confinement building, was dissolved in Roswell Park 
Memorial Institute (RPMI) 1640 medium (Gibco Laboratories, Paisley, UK), sonicated for $10 \mathrm{~min}$ and diluted in heparinized whole blood to a final concentration of $50 \mu \mathrm{g} \cdot \mathrm{mL}^{-1}$. The polyclonal activator, phytohaemagglutinin (PHA), used as positive control, was also dissolved in RPMI 1640 and sonicated for $10 \mathrm{~min}$ and diluted in whole blood to a final concentration of $10 \mu \mathrm{g} \cdot \mathrm{mL}^{-1}$. Unstimulated whole blood containing RPMI 1640, was used as negative control. Blood samples were incubated for $24 \mathrm{~h}$ and then ethylenedianmine tetracetic acid (EDTA) was added to a final concentration of $5 \mathrm{mM}$. All stimulation tests were performed in duplicate during $24 \mathrm{~h}$ in $37^{\circ} \mathrm{C}$ and $5 \% \mathrm{CO}_{2}$.

Blood was collected using Vacutainer $\mathbb{R}$ brand blood collection tubes, and Vacutainer $\AA \mathrm{CPT}^{\mathrm{TM}}$, (Cell Preparation Tubes, Becton Dickinson Vacutainer Systems, Franklin Lakes, NJ, USA) containing sodium heparin anticoagulant. Peripheral blood mononuclear cells (PBMC) were selected through gradient separation. In a first experimental set-up PBMC was incubated with plasma received from whole blood previously incubated with $50 \mu \mathrm{g} \cdot \mathrm{mL}^{-1}$ swine dust, i.e. "conditioned plasma", $10 \mu \mathrm{g} \cdot \mathrm{mL}^{-1}$ PHA or RPMI for $24 \mathrm{~h}$. In a second experimental set-up, PBMC was resuspended in autologous plasma and incubated with $50 \mu \mathrm{g} \cdot \mathrm{mL}^{-1}$ swine dust, $10 \mu \mathrm{g} \cdot \mathrm{mL}^{-1}$ PHA or RPMI for $24 \mathrm{~h}$.

Phagocytic cells were removed from whole blood through incubation with carbonyl iron particles $\left(4 \mu \mathrm{g} \cdot \mathrm{mL}^{-1}\right.$, size $5 \mu \mathrm{g}$, Sigma Aldrich, Stockholm, Sweden). Blood and carbonyl iron particles were incubated for $30 \mathrm{~min}$ at $37^{\circ} \mathrm{C}$ and mixed occasionally. After incubation, the blood sample tube was placed on one of the pools of a magnet (Dynal A.S., Oslo, Norway) for $10 \mathrm{~min}$ at $4{ }^{\circ} \mathrm{C}$. The noniron containing i.e. the nonphagocytic cells were removed (with the tube still standing on the magnet) and transferred to a second plastic tube. Cells were resettled on the magnet for a further $10 \mathrm{~min}$ at $4^{\circ} \mathrm{C}$ and the procedure was repeated. Blood was stained with the monoclonal antibody CD14-PE/CD45-FITC (Becton Dickinson, Franklin Lakes, NJ, USA) before and after iron incubation. The nonphagocytic cells were incubated with $50 \mu \mathrm{g}$ swine dust $\cdot \mathrm{mL}^{-1}, 10 \mu \mathrm{g} \mathrm{PHA} \cdot \mathrm{mL}^{-1}$ or with RPMI 1640 (negative control) for $24 \mathrm{~h}$.

\section{Monoclonal antibodies and flow cytometric analysis}

Cells were characterized by subgroup-specific fluorochrome-conjugated monoclonal antibodies. For analysis of T-cell activation, double staining for CD3 and the cell-surface activation marker CD69 (Becton Dickinson) was performed. Monocyte depletion was evaluated and analysed by CD14-PE/CD45-FITC. Twenty microlitres of monoclonal antibody was added to $100 \mu \mathrm{L}$ aliquots of either blood or PBMC samples dissolved in plasma. The samples were incubated $20 \mathrm{~min}$ in the dark, at room temperature. Lysing of red blood cells, was done using fluorescence-activated cell sorter (FACS) lysing solution (Becton Dickinson) and fixation was achieved by using Cellfix (Becton Dickinson). For background staining, isotypic controls were performed. Cell count percentages were calculated by flow cytometry using a FACS Calibur (Becton Dickinson).

\section{Cytokine analyses by enzyme-linked immunosorbent assay}

IL-12 in plasma samples was analysed by Human IL-12 immunoassay (R\&D System Europe Ltd, Abingdon, UK). Interferon (IFN)- $\gamma$ in plasma samples was analysed by OptEIA ${ }^{\text {TM }}$ Human IFN- $\gamma$ Kit (PharMingen, San Diego, CA, USA).

\section{Statistics}

Statistical analysis was performed using StatView $\mathbb{R}$ programme, version 4.02 for Macintosh and Super Anova 1.11 (Abacus Concepts, Inc, Berkeley, CA, USA). Results are presented as medians (25-75th percentiles). Comparisons were performed by analysis of variance (ANOVA). P-values $<0.05$ were considered to be statistically significant.

\section{Results}

After 24-h incubation of whole blood in vitro $27.6 \%$ (17.3-30.8) of the CD3 positive lymphocytes (T-cells) expressed the early activation marker CD69 compared to $3.3 \%(2.2-4.4)$ of T-lymphocytes in nonstimulated whole blood $(\mathrm{p}<0.0001)$. Incubation with PHA and whole blood yielded $71.3 \%(65.3-73.4)$ of the T-lymphocytes to express CD69 (fig. 1).

In PBMC selected from whole blood and incubated with dust for $24 \mathrm{~h}$ CD69 was expressed in $4.8 \%$ (4.5-7.0) of the T-cells compared to $2.2 \%(1.5-3.1)$ of T-lymphocytes from nonstimulated PBMC (not significant). PHA induced CD69 expression in $70.9 \%$ (36.0-78.8) of the T-lymphocytes in PBMC (fig. 1).

Phagocytic cells were removed from whole blood through incubation with carbonyl iron, reducing the proportion of monocytes from 7 to $1 \%$ and of granulocytes from 58 to $35 \%$ (median value). In such "phagocyte reduced" whole blood, incubation with dust for $24 \mathrm{~h}$ induced CD69 expression in $4.5 \%$ (3.6-9.7) of the T-lymphocytes as compared to $1.5 \%$ (1.2-1.7) in T-lymphocytes of nonstimulated "phagocyte reduced" whole blood (not significant). Incubation with PHA as a positive control induced CD69 expression on $71.3 \%(59.1-79.2)$ of the T-lymphocytes (fig. 1).

Plasma was transferred from dust-exposed whole blood, i.e. "conditioned plasma", and incubated with PBMC for $24 \mathrm{~h}$. Following this incubation, $32.4 \%(29.2-34.4)$ of the CD3 positive T-lymphocytes expressed CD69 compared to $3.3 \%(2.8-3.6)$ of T-lymphocytes of PBMC incubated with control plasma $(\mathrm{p}<0.0001)$. Plasma from whole blood stimulated with PHA induced expression of CD69 in 37.1\% (30.0-52.1) of the T- lymphocytes (fig. 2). 


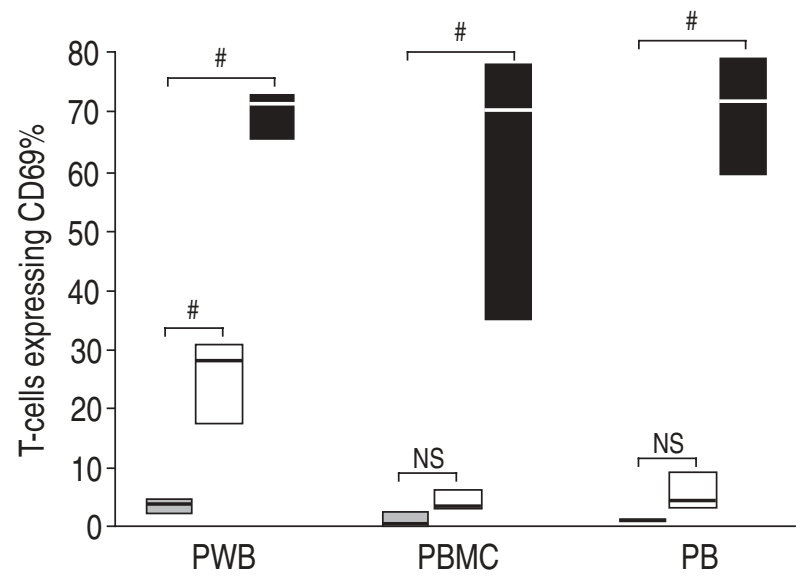

Fig. 1.-CD69 expression of T-lymphocytes $(\%$ of CD3 positive cells) in peripheral whole blood (PWB), peripheral blood mononuclear cells (PBMC) resuspended in autologous plasma and peripheral blood depleted from phagocytic cells (PB), following incubation with either Roswell Park Memorial Institute medium (control: $\square$ ), swine dust $(\square)$ or phytohaemoglutin $(\square)$ for $24 \mathrm{~h}$. Values are presented as median values and interquartile ranges. NS: no significant difference; \#: $\mathrm{p}<0.0001$ compared to unstimulated cells.

\section{Soluble mediators in conditioned plasma}

In an attempt to identify soluble mediators of importance for the T-lymphocyte stimulation, the concentration of IL-12 and IFN- $\gamma$ in conditioned plasma was measured. In the dust incubated whole blood, i.e. the conditioned plasma, the IL-12 concentration was $14.1(8.3-22.1) \mathrm{pg} \cdot \mathrm{mL}^{-1}$, while the concentration was below detection limit in control plasma. Plasma from PHA stimulated whole blood contained 47.4 (25.7-73.2) $\mathrm{pg} \cdot \mathrm{mL}^{-1} \mathrm{IL}-12$. In plasma of PBMC stimulated with dust, the IL-12 concentration was $2.3(0.1-2.8) \mathrm{pg} \cdot \mathrm{mL}^{-1}$. PHA stimulated PBMC supernatant contained 5.9 (3.5-10.6) $\mathrm{pg} \cdot \mathrm{mL}^{-1}$, while negative controls had undetectable levels (fig. 3).

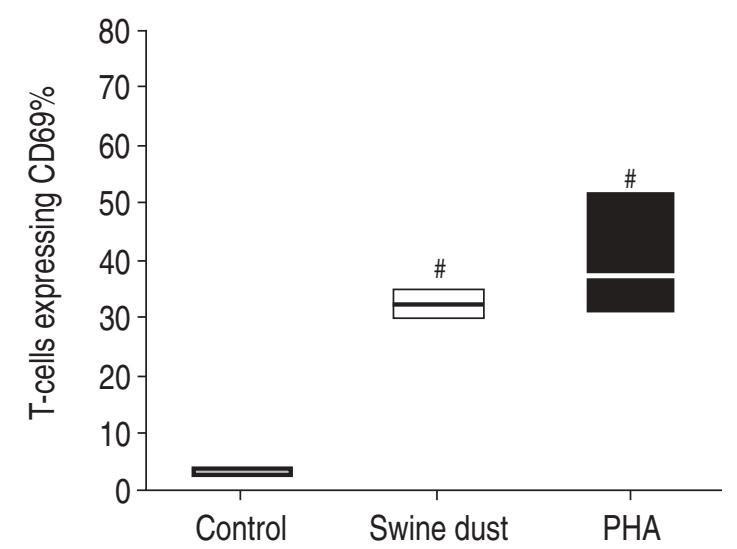

Fig. 2.-CD69 expression of T-lymphocytes (\% of CD3 positive cells) in peripheral blood mononuclear cells (PBMC) following $24 \mathrm{~h}$ incubation with Roswell Park Memorial Institute medium (RPMI: control), plasma from swine dust (white box) or phytohaemoglutin (PHA: black box) stimulated whole blood. Values are presented as median values and interquartile ranges. \#: $\mathrm{p}<0.0001$ compared to control.
IFN- $\gamma$ levels in conditioned plasma were 2284.1 (1352.8-4025.9) $\mathrm{pg} \cdot \mathrm{mL}^{-1}$ compared to 4775.8 (3936.29381.8) $\mathrm{pg} \cdot \mathrm{mL}^{-1}$ in PHA stimulated plasma and 6.5 $(0.7-32.6) \mathrm{pg} \cdot \mathrm{mL}^{-1}$ in control plasma. PBMC plasma from swine dust incubations contained 195.9 (161.2364.9) $\mathrm{pg} \cdot \mathrm{mL}^{-1}$ compared to $804.1(286.7-863.0) \mathrm{pg} \cdot \mathrm{mL}^{-1}$ in PHA stimulated PBMC and $6.0(1.9-15.0) \mathrm{pg} \cdot \mathrm{mL}^{-1}$ in control supernatant (fig. 3).

\section{Discussion}

In line with the authors' previous findings [8] the present study demonstrates that swine dust activates T-lymphocytes in whole blood in vitro, as detected by T-cell expression of the early activation marker CD69. However, when incubating swine dust with PBMC separated from whole blood, T-lymphocytes were not activated. In contrast to whole blood, PBMC consists mainly of lymphocytes, while there are virtually no granulocytes and only few monocytes. To further investigate whether phagocytic cells such as granulocytes and monocytes could influence the dustmediated activation of T-lymphocytes, the number of monocytes and granulocytes in whole blood were reduced, which substantially reduced the capacity of the dust to activate T-lymphocytes. Organic dust obtained from swine confinement houses is therefore capable of activating T-lymphocytes only in the presence of phagocytic cells. Moreover, plasma from swine dust exposed whole blood, i.e. conditioned plasma induced lymphocyte activation. Based on these data the present authors conclude that T-cell activation induced by dust requires phagocytic cells and that it is induced by mediator release from phagocytic rather than by a direct cell-to-cell interaction.

The present authors previously found dramatically increased numbers of inflammatory cells, especially neutrophilic granulocytes, in BAL fluid after exposure to swine dust in vivo. Increased concentrations of TNF- $\alpha$, IL -1, IL-6 and IL-8 were also found in BAL fluid following exposure to swine dust in vivo $[3,4]$ and in supernatant of epithelial cells and alveolar macrophages following exposure to dust in vitro [9, 10]. Granulocytes have also been shown to release many of these cytokines, i.e. TNF- $\alpha$, IL -1, and IL-8 upon lipopolysaccharide (LPS) stimulation [11-15], and monocytes can produce TNF- $\alpha$ [16], IL-1, [15, 17, 18] and IL-12 [19]. Many of these granulocytes and monocytes derived cytokines are involved in the activation of lymphocytes, either directly (IL-1, IL-6, IL-12) or indirectly (IFN- $\gamma$ ). In the present study, high levels of IL-12 and IFN- $\gamma$ were found in conditioned plasma following in vitro exposure of whole blood to dust. Thus phagocytic cells such as granulocytes and monocytes present in whole blood during swine dust incubation seem to release cytokines IL-12 and IFN- $\gamma$ which may be of importance for the swine dust induced T-lymphocyte stimulation. It seems likely that monocytes produce cytokines such as IL-12, which may induce IFN- $\gamma$ production by lymphocytes such as natural killer (NK) cells.

To conclude, phagocytic cells are necessary for the dust-activation of T-lymphocytes. The phagocytes 
a)

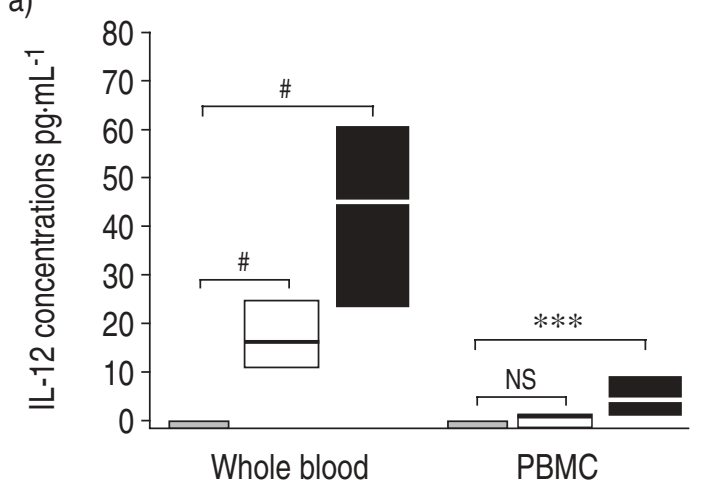

b)

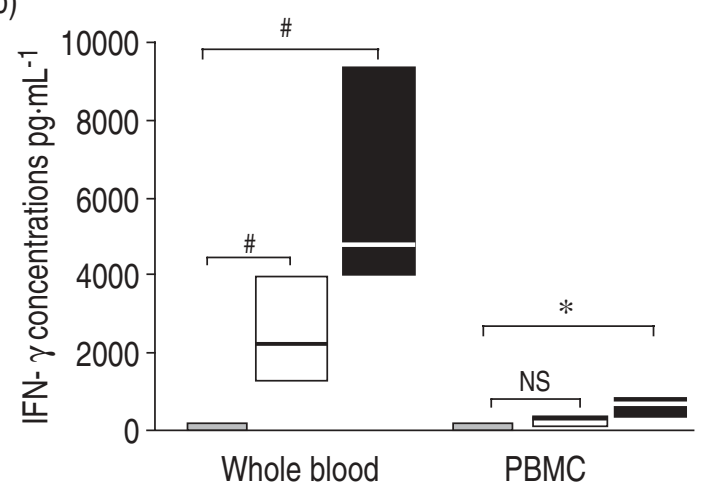

Fig. 3.-Interleukin (IL)-12 and interferon (IFN)- $\gamma$ concentrations in plasma from whole peripheral blood and peripheral blood mononuclear cells (PBMC), incubated with either Roswell Park Memorial Institute medium (RPMI) (control: $\square$ ), swine dust ( $\square$ ) or phytohaemoglutin $(\mathbf{\square})$ for $24 \mathrm{~h}$. Values are presented as median values and interquartile ranges. NS: no significant difference; $*$ : p $<0.05$; $* * *: \mathrm{p}<0.001 ;{ }^{\#}: \mathrm{p}<0.0001$ compared to unstimulated cells.

seem to act by releasing lymphocyte-activating cytokines such as interleukin-12 and interferon- $\gamma$. To improve the understanding of immune response following exposure to organic dust, intracellular cytokine release from swine-dust activated peripheral blood cells as well as bronchoalveolar lavage cells from dustexposed individuals will need to be studied in vivo.

\section{References}

1. Larsson K, Eklund A, Hansson LO, Isaksson BM, Malmberg P. Swine dust cause intense airways inflammation in healthy subjects. Am J Respir Crit Care Med 1994; 150: 973-977.

2. Wang Z, Malmberg P, Larsson P, Larsson B-M, Larsson K. Time course of IL-6 and TNF-alpha in serum following inhalation of swine dust. Am J Respir Crit Care Med 1996; 153: 147-152.

3. Wang Z, Palmberg L, Malmberg P, Larsson P, Larsson L. Inhalation of swine dust induces cytokine release in the upper and lower airways. Eur Respir $J$ 1997; 10: 381-387.

4. Larsson B-M, Palmberg L, Malmberg PO, Larsson K. Effect of exposure to swine dust on levels of IL-8 in airway lavage fluid. Thorax 1997; 52: 638-642.

5. Rankin JA, Sylvester I, Smith S, Yoshimura T, Leonard EJ. Macrophages cultured in vitro release leukotriene B4 and neutrophil attractant/activation protein (interleukin-8) sequentially in response to stimulation with lipopolysaccharide and zymosan. $J$ Clin Invest 1990; 86: 1556-1564.

6. Bédard M, McClure CD, Schiller NL, Francoeur C, Cantin A, Denis M. Release of Interleukin-8, (Interleukin-8, and Colony stimulating factors by upper airway epithelial cells: Implications for cystic fibrosis. Am J Respir Cell Mol Biol 1993; 9: 455-462.

7. Müller-Suur C, Larsson KA, Malmberg PO, Larsson $\mathrm{PH}$. Increased number of activated lymphocytes in human lung following swine dust inhalation. Eur Respir J 1997; 10: 376-380.

8. Müller-Suur C, Larsson PH, Larsson K. T-cell activation by organic dust in vitro. Respir Med 2000; 94: 821-827.

9. Palmberg L, Larsson BM, Malmberg P, Larsson K. Induction of IL-8 production in human alveolar macrophages and human bronchal epithelial cells in vitro by swine dust. Thorax 1998; 53: 260-264.

10. Wang Z, Malmberg P, EK A, Larsson K, Palmberg L. Swine dust induces cytokine secretion from human epithelial cells and alveolar macrophages. Clin Exp Immunol 1999; 115: 6-12.

11. Cassatella MA, Bazzoni F, Ceska M, Ferro L, Baggiolini M, Berton G. IL-8 production by human polymorphonuclear leukocytes. The cemoattractant forml-methinonyl-leucyl-phenylanine induces the gene expression and release of IL-8 through a pertussis toxin-sensitive pathway. J Immunol 1992; 148: 32163320.

12. Streiter RM, Kashahara K, Standiford TJ, Rolfe MW, Chensue SW, Kunkel SL. Cytokine induced neutrophil derived interleukine-8. Am J Pathol 1992; 141: 397-407.

13. Fujishima $\mathrm{S}, \mathrm{Hoffman} \mathrm{AR}, \mathrm{Vu} \mathrm{T}$, et al. Regulation of neutrophil interleukine 8 gene expression and protein secretion by LPS, TNF-alpha, and IL-beta. J Cell Physiol 1993; 154: 478-485.

14. Dubravec DB, Spriggs DR, Mannick JA, Rodrick ML. Circulating human peripheral blood granulocytes synthesize and secrete tumor necrosis factor alpha. Proc Natl Acad Sci USA 1990; 87: 6758-6761.

15. Lord PC, Wilmoth LM, Mizel SB, McColl CE. Expression of IL-1 alpha and beta genes by human blood polymorphonuclear leukocytes. J Clin Invest 1991; 87: 1312-1321.

16. Sherry B, Cerami A. Cachectin/tumournecrosis factor exerts endocrine, paracrine and autocrine control of inflammatory responses. J Cell Biol 1988; 107: 12691277.

17. Fenton MJ, Vermeulen MW, Clark BD, Webb AC, Auron PE. Human pro-IL-1 beta gene expression in monocytic cellsus regulated by two distinct pathways. J Immunol 1988; 140: 2267-2673.

18. Jenkins JK, Malyak M, Arend WP. The effects of interleukin-10 on interleukin-1 receptor antagonist and interleukin-1 beta production in human monocytes and neutrophils. Lymphokine Cytokine Res 1994; 13: 47-54.

19. D'Andrea A, Rengaraju M, Valiante NM. Production of natural killer cell stimulatory factor (Interleukin12) by peripheral blood mononuclear cells. J Exp Med 1992; 176: 1387-1398. 